\title{
Buckling Analysis of Composite Timoshenko Beams with Gâteaux Differential
}

\author{
Gülçin Tekin, Fethi Kadıŏglu
}

\begin{abstract}
In this study, buckling analysis of composite Timoshenko beam is conducted and a functional is presented by applying mixed finite element method with Gâteaux differential. Mixed finite element model has four unknowns, deflection, bending moment, rotation and shear force. For the analysis, composite straight beams with different boundary conditions are considered. Accuracy of the presented functional and mixed finite element formulation is shown by comparing the results of numerical examples with the ones available in the literature. The results obtained in this study are found to be in good agreement.
\end{abstract}

Keywords-buckling, composite Timoshenko beams, functional analysis method, Mixed Finite Element Method

\section{Introduction}

Composite materials have high strength when compared to isotropic materials, easily shaped and light due to their specific weight. There are lots of studies in literature about composite materials. Studies in literature generally present approximate solution of the problem with Finite Element Method (FEM), Finite Difference Method, Rayleigh-Ritz Method and Galerkin Method instead of the exact solution. In this study, Mixed-Finite Element Method with Gâteaux differential is used. This method is applied to elastic, viscoelastic and composite beams [1-4]. Detail information about Gâteaux differential can be found in the literature [5]. Gün [6] analyzed buckling problem of elastic straight bars and presented a new functional by using Gâteaux differential with functional analysis method. The free vibration and buckling behaviors of composite beams are mostly studied in the literature. R.Xu and Y.F.Wu [7] studied buckling and free vibration of composite beams by two-dimensional theory. R.Xu and Y.F.Wu [8] used Timoshenko's beam theory for static, dynamic and buckling analysis of composite members. M.A.R. Loja, J.I.Barbosa and C.M.M. Soares [9] studied buckling behavior of laminated beam structures using a higher-order discrete model. In this study, critical buckling loads are calculated for composite straight orthotropic Timoshenko beams with different boundary conditions. Different from other studies, Gâteaux derivative and functional analysis method is used to determine functional of Timoshenko beam. Mixed finite element method is used for derivation of element matrices by selecting the linear shape functions. In order to verify the accuracy of the derived functional and presented mixed finite element formulation, numerical examples are solved and compared with other published solutions.

Gülçin Tekin, Fethi Kadığlu

Istanbul Technical University Turkey
It has been shown that, the presented mixed finite element formulation can accurately predict the critical method buckling loads of composite orthotropic Timoshenko beams.

\section{Method}

Field equations of straight bars can be found from literature [10]. In the field equations, there are four variables including a bending moment $(M)$, a component of deflection $(v)$, a rotation $(\Omega)$ and a shear force $(T)$. The reader is referred to [11] for detail information about the derivation of field equations of Timoshenko beam. Equilibrium, constitutive and field equations can be written in operator form as

$$
\begin{aligned}
& \mathbf{L u}-\mathbf{f}=\mathbf{0} \\
& \mathbf{Q}=\mathbf{L u}-\mathbf{f} .
\end{aligned}
$$

where $\mathbf{Q}$ is a potential if the equality

$$
\left\langle\mathrm{d} \mathbf{Q}(\mathbf{u}, \overline{\mathbf{u}}), \mathbf{u}^{*}\right\rangle=\left\langle\mathrm{d} \mathbf{Q}\left(\mathbf{u}, \mathbf{u}^{*}\right), \overline{\mathbf{u}}\right\rangle .
$$

is satisfied. Where $\mathbf{d Q}(\mathbf{u}, \overline{\mathbf{u}})$ is the Gâteaux derivative of $\mathbf{Q}$ and the inner product to two vectors. Therefore, the functional corresponding to the field equations is obtained as

$$
\mathrm{I}(\mathbf{u})=\int_{0}^{1}\langle\mathbf{Q}(\mathrm{s} \mathbf{u}, \mathbf{u}), \mathbf{u}\rangle \mathrm{ds} .
$$

where $\mathrm{s}$ is a scalar quantity. Details of variational procedures can be found in [11]. Finally from (3), the functional of composite straight beam for Timoshenko beam becomes

$$
\begin{aligned}
& I(\mathbf{u})=\frac{N}{2}\left[v^{\prime}, v^{\prime}\right]-\left[v^{\prime}, T\right]-\left[M, \Omega^{\prime}\right]-[T, \Omega] \\
& +\frac{1}{2 D_{n}}[M, M]+\frac{1}{2 C_{b}}[T, T]+[\Omega, \hat{M}]_{\sigma}+[v, \hat{H}]_{\sigma} \\
& +[M,(\Omega-\hat{\Omega})]_{\varepsilon}+[H,(v-\hat{v})]_{\varepsilon}
\end{aligned}
$$

where subscript, $\sigma$ represents dynamic boundary condition, $\varepsilon$ represents geometric boundary condition. In addition, $D_{n}$ and $C_{b}$ are the bending rigidity and shear rigidity of the beam, respectively. $N$ is the axial force and $H$ is the horizontal force. Element matrix derived for buckling analysis, convert to the eigenvalue problem as below:

$$
\left(\left[K^{*}\right]-P_{c r}[\overline{\mathrm{m}}]\right)\{v\}=\{0\} .
$$




$$
\left[K^{*}\right]=\left[K_{22}\right]-\frac{\left[K_{21}\right]\left[K_{12}\right]}{\left[K_{11}\right]} .
$$

where $\mathrm{K}^{*}$ represents reduced system matrices. Solution of this equation set is satisfied when coefficient determinant equals to zero.

\section{Numerical Example}

\section{Example 1:}

For buckling analysis of composite straight Timoshenko beam, a length of $\mathrm{L}=10 \mathrm{~m}$, a width of $\mathrm{b}=1 \mathrm{~m}$, and a thickness of $\mathrm{h}=1 \mathrm{~m}$ beam is considered. The material properties are given as:

TABLE I. MATERIAL PROPERTIES

\begin{tabular}{|c|c|c|c|c|c|}
\hline $\mathbf{E}_{\boldsymbol{1}}$ & $\boldsymbol{E}_{\boldsymbol{3}}$ & $\boldsymbol{G}_{\boldsymbol{1} \boldsymbol{2}}$ & $\boldsymbol{G}_{\boldsymbol{1 3}}$ & $\boldsymbol{G}_{\boldsymbol{2 3}}$ & $\boldsymbol{v}_{\boldsymbol{1}}$ \\
\hline $25 \mathrm{E}_{2}$ & $\mathrm{E}_{2}$ & $0,5 \mathrm{E}_{2}$ & $0,5 \mathrm{E}_{2}$ & $0,2 \mathrm{E}_{2}$ & 0,25 \\
\hline
\end{tabular}

The beam is characterized by 20 equal length beam finite elements. Equation (7) is used for dimensionless modulus.

$$
\bar{P}_{c r}=\frac{P_{c r} L^{2}}{b E_{2} h^{3}}
$$

Table II shows the dimensionless critical buckling load $\left(\bar{P}_{c r}\right)$ of composite beams, with three different boundary conditions, for different length-to-thickness ratios $\mathrm{L} / \mathrm{h}=10$, $20,100$.

TABLE II. DIMENSIONLESS CRITICAL BUCKLING LOADS $\left(\bar{P}_{c r}\right)$ FOR

\begin{tabular}{|c|c|c|c|}
\hline $\mathbf{L} / \mathbf{h}$ & Boundary Condition & Present & $\operatorname{Ref}[10]$ \\
\hline \multirow{3}{*}{10} & Hinged-Hinged & 13,739 & 13,768 \\
\hline & Fixed-Fixed & 27,359 & 27,656 \\
\hline & Fixed-Free & 4,666 & 4,576 \\
\hline \multirow{3}{*}{20} & Hinged-Hinged & 18,265 & 18,304 \\
\hline & Fixed-Fixed & 54,893 & 55,07 \\
\hline & Fixed-Free & 5,034 & 4,987 \\
\hline \multirow{3}{*}{100} & Hinged-Hinged & 20,418 & 20,461 \\
\hline & Fixed-Fixed & 79,852 & 80,655 \\
\hline & Fixed-Free & 5,147 & 5,134 \\
\hline
\end{tabular}
COMPOSITE TIMOSHENKO BEAMS

It can be seen from Table II that the results obtained in this study agree well with those available in the literature, so the methodology of this study is reliable. And the beam with one end fixed and another end free has the minimum critical buckling load as compared with the boundary conditions Fixed-Fixed and Hinged-Hinged. In addition, by increasing the $\mathrm{L} / \mathrm{h}$ ratio, critical buckling load values increase.

\section{Example 2:}

As a second example, composite straight Timoshenko beam with hinged-hinged boundary condition is considered. The length of the beam is $L=10 \mathrm{~m}$, width of the beam is $b=1$ $\mathrm{m}$. Thickness of the beam is changed in order to determine the critical buckling loads for different $h / b$ ratios. The numerical results obtained by the present study for various thickness of the beam $(\mathrm{h}=0,25 \mathrm{~m} ; 0,5 \mathrm{~m}$ and $1 \mathrm{~m})$. The beam is characterized by 20 equal length beam finite elements. The material properties are given in Table III and $\mathrm{E}_{2}=21 \mathrm{x}$ $10^{5} \mathrm{~N} / \mathrm{m}^{2}$.

TABLE III. MATERIAL PROPERTIES

\begin{tabular}{|c|c|c|c|c|c|}
\hline $\mathbf{E}_{\boldsymbol{1}}$ & $\boldsymbol{E}_{\boldsymbol{3}}$ & $\boldsymbol{G}_{\boldsymbol{1 2}}$ & $\boldsymbol{G}_{\boldsymbol{1 3}}$ & $\boldsymbol{G}_{\mathbf{2 3}}$ & $\boldsymbol{v}_{\boldsymbol{1 2}}$ \\
\hline $40 \mathrm{E}_{2}$ & $\mathrm{E}_{2}$ & $0,6 \mathrm{E}_{2}$ & $0,6 \mathrm{E}_{2}$ & $0,5 \mathrm{E}_{2}$ & 0,25 \\
\hline
\end{tabular}

In order to validate the method developed in this paper the critical buckling loads (Newton "N") are compared with the theoretical results available in the literature as shown in Table IV, using different thickness to width ratios. It can be seen that the results obtained in this study agree well with the theoretical results available in the literature, so the model and methodology of this study are reliable. In addition, by increasing the $\mathrm{h} / \mathrm{b}$ ratio, critical buckling load values increase.

TABLE IV. CRITICAL BUCKLING LOADS, $P_{C R}$, (IN NEWTON) OF TIMOSHENKO BEAMS FOR DIFFERENT THICKNESS-TO-WIDTH RATIOS

\begin{tabular}{|c|c|c|c|}
\cline { 2 - 4 } \multicolumn{1}{c|}{} & $\boldsymbol{h} / \boldsymbol{b}=\mathbf{0 , 2 5}$ & $\boldsymbol{h} / \boldsymbol{b}=\mathbf{0 , 5}$ & $\boldsymbol{h} / \boldsymbol{b}=\mathbf{1}$ \\
\hline$P_{c r}$ (theoretical) & 10367 & 82947 & 416696 \\
\hline$P_{c r}$ (present) & 10390 & 82224 & 415834 \\
\hline
\end{tabular}

\section{Conclusion}

In this study, with Gâteaux differential method a new functional corresponding to the composite straight orthotropic Timoshenko beam is presented. For the analysis, mixed finite element method is used to obtain element matrices. Functional of Timoshenko beam has four unknowns, deflection $(v)$, bending moment $(M)$, shear force $(T)$ and rotation $(\Omega)$ in each node. For the solutions of functional, linear shape functions are used because of only first-order derivation exists in functional.

The values of the critical buckling loads are obtained for composite straight beams with different boundary conditions and different geometrical properties. For analysis of orthotropic straight beams, hinged-hinged, fixed-fixed and fixed-free boundary conditions are used. The results show that Timoshenko beam with fixed-fixed end has maximum buckling load. And the beam with one end fixed and another end free has the minimum critical buckling load as compared with the other boundary condition types. Moreover, by increasing the $\mathrm{L} / \mathrm{h}$ ratio, critical buckling load values increase. In addition, by increasing the $\mathrm{h} / \mathrm{b}$ ratio of the beam, critical buckling load values increase.

The performance of the presented mixed finite element formulation is verified by comparing the obtained results with the results of the numerical examples in the literature. The numerical results are found to be in good agreement with those available in the literature. 


\section{References}

[1] A. Y. Aköz, F. Kadıŏlu, "The mixed finite element solution of circular beam on elastic foundation," Computers and Structures, vol. 60(4), pp. 643-651, 1996

[2] A. Y. Aköz, F. Kadıŏglu, "The mixed finite element method for quasi-static and dynamic analysis of viscoelastic Timoshenko beams, "International Journal for Numerical Methods in Engineering, vol. 44(12), pp. 1909-1932, 1999.

[3] F. Kadığlu, A. Y. Aköz, "The mixed finite element method for the quasi-static and dynamic analysis of viscoelastic circular beams," International Journal Structural Engineering and Mechanics, vol.15(6), pp. 735-752, 2003.

[4] F. Kadığlu, C. İyidoğan, “ Free vibration of laminated composite curved beams using mixed finite element formulation, "Science and Engineering of Composite materials, vol. 16(4), pp. 247-257, 2009.

[5] J. D. Oden, J. N. Reddy, Variational Methods In Theoretical Mechanics. Springer, Berlin, 1976.

[6] T. Gün, "A New functional for buckling analysis of straight bars and its finite element solution, " Master Thesis, Istanbul (in Turkish), 2002.

[7] R. Xu, Y. F. Wu, "Free vibration and buckling of composite beams with interlayer slip by two-dimensional theory, "Journal of Sound and Vibration, vol. 313, pp. 875-890, 2008.

[8] R. Xu, Y. F. Wu, "Static, dynamic, and buckling analysis of partial interaction composite members using Timoshenko's beam theory," International Journal of Mechanical Sciences, vol. 49, pp.1139-1155, 2007.

[9] M. A. R. Loja, Barbosa J. I., Soares C. M. M, "Buckling behavior of laminated beam structures using a higher-order discrete model," Composite Structures, vol. 38(1-4), pp. 119-131, 1997.

[10] J. N. Reddy, Mechanics of Laminated Composite Plates and Shells: Theory and Analysis. 2nd ed. Boca Raton, Fl:Crc Press, 2004.

[11] G. Özkan, "Buckling analysis of cross-ply laminated composite straight beams, " Master thesis, Istanbul (in Turkish), 2011.

About Author (s):

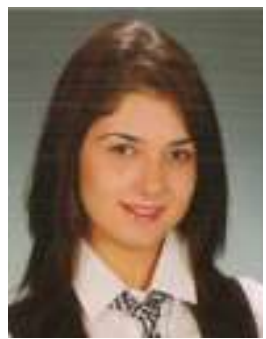

Gülçin Tekin received her BSc degree in Civil Engineering from Yildı Technical University, Istanbul, Turkey. She completed MSc degree at the Bogaziçi University, Istanbul, Turkey. She is currently a thirdyear PhD student in the department of Civil Engineering at the Istanbul Technical University, Istanbul, Turkey. Presently she is working as a research assistant at Istanbul Technical University. Her areas of interest are Structural Analysis, Mixed Finite Element Methods.

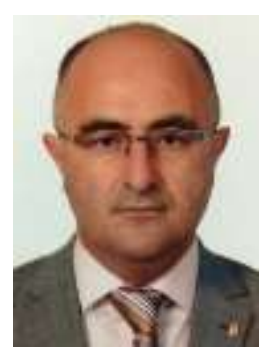

Dr. Fethi Kadığglu received his BSc, MSc and $\mathrm{PhD}$ from Istanbul Technical University, Istanbul, Turkey. He is currently working as an Associate Prof. in the Department of Civil Engineering at Istanbul Technical University. He published over 35 papers in international journals and conferences, 5 books and book chapters in the fields of Structural Mechanics. Dr. Kadığlu's current research interests include: Composite Structures, Stability of Structures and Vibration, Elastic, Viscoelastic Analysis, Structural Analysis and Finite Element Methods. 